\title{
COVID Toes: Digital Vascular Changes in Patients with a COVID-19 Infection
}

\section{Justin Chin $^{1 *}$ | Ryan D. Rivera ${ }^{2}$ | Christine Lomiguen ${ }^{3}$ | Simrat K. Veera ${ }^{4}$ | Vilma A. Joseph ${ }^{5}$ | Nanette Silverberg6 ${ }^{6}$ Mary Lee-Wong ${ }^{7}$}

\section{*Correspondence: Justin Chin}

Address: ${ }^{1}$ Department of Family Medicine, Lifelong Medical Care, Richmond CA, USA; ${ }^{2}$ Department of Dermatology, Mount Sinai Health System, New York NY, USA; ${ }^{3}$ Department of Pathology, Lake Erie College of Osteopathic Medicine, Erie PA, USA; ${ }^{4}$ Department of Pediatrics, Goryeb Children's Hospital-Atlantic Health System, Morristown NJ, USA; ${ }^{5}$ Department of Anesthesiology, Montefiore Medical Center, New York NY, USA; ${ }^{6}$ Department of Pediatric Dermatology, Mount Sinai Health System, New York NY, USA; ${ }^{7}$ Department of Allergy and Immunology, Beth Israel Mount Sinai, New York NY, USA e-mail $\bowtie$ : justinchindo@gmail.com

Received: 12 May 2020; Accepted: 28 May 2020

Copyright: (C) 2020 Chin J. This is an open-access article distributed under the terms of the Creative Commons Attribution License, which permits unrestricted use, distribution, and reproduction in any medium, provided that the original work is properly cited.

\section{ABSTRACT}

COVID-19 is a highly infectious disease caused by the SARS-CoV2 virus and has resulted in a global pandemic. Primarily understood as a respiratory disease, ongoing studies have observed the effects of COVID-19 on other body systems. COVID toes, also known as pseudo-chilblains, is an increasingly common dermatological condition in which pruritic, erythematous rashes appear on the toes. Generally benign in adults, COVID toes have also been observed in Multisystem Inflammatory Syndrome in Children (MIS-C) associated with COVID-19. Here we present a case of a 9-year-old Hispanic asymptomatic COVID-19 male and a 53-year-old African American female with symptomatic, confirmed COVID-19, with a comparison of the prognostic differences between children and adults of COVID toes and a review of the current literature.

Keywords: COVID Toes, COVID-19, Pseudo-Chilblains, Pandemic, Pernio

\section{Introduction}

COVID-19 is a highly infectious viral illness caused by the severe acute respiratory syndrome coronavirus 2 or SARS-CoV2 virus (Ahn et al., 2020). As a coronavirus, COVID-19 attacks alveolar cells in the respiratory system causing pneumonitis (Hamming et al., 2004). However, this is a tremendous oversimplification, as COVID-19 in select individuals appears to trigger a variety of immune phenomena resulting in multi-system damage (Huang et al., 2020). Colloquially known as the coronavirus, COVID-19 has evolved from a local outbreak to a global pandemic, resulting in over 4 million infections and 300 thousand deaths worldwide (Lai et al., 2020). Due to its high pathogenicity and transmissibility, largescale changes to social interactions have altered the fabric of human interactions through social distancing measures, widespread shutdown of economies, closure of schools and non-essential businesses, and the curtailment of travel and large gatherings (Matrajt and Leung, 2020; Prem et al., 
2020). Current knowledge of COVID-19's clinical presentation and treatment options have been rapidly evolving, with ongoing research revealing new discoveries on a daily basis.

Recent studies have highlighted new dermatological findings related to COVID-19 from assorted constellations of benign rashes in adults to a more deadly Multisystem Inflammatory Syndrome in Children (MIS-C) associated with COVID-19 (Andina et al., 2020; Belhadjer et al., 2020; Galván Casas et al., 2020; Nirenberg and Del Mar Ruiz Herrera, 2020). COVID toes, a type of benign pseudo-chilblains, were one of the first rashes ascribed to COVID-19, however its significance as a diagnostic tool or prognosticator for recovery are still largely being investigated (Cordoro et al., 2020; Zhang et al., 2020). With a spectrum of physical manifestations, consistent diagnosis of COVID toes may pose a challenge for physicians and patients alike, especially in the context of asymptomatic COVID-19 (Galván Casas et al., 2020).

Here we present a case of a 9-year-old Hispanic asymptomatic COVID-19 male and a 53-year-old African American female with symptomatic, confirmed COVID-19, with a comparison of the prognostic differences between children and adults with COVID toes and a review of the current literature.

\section{Case Presentations}

Case 1

A 53-year-old African American physician female presented to an allergic clinic for recent onset skin lesions of the bilateral ten toes. Her past medical history included hypertension, hyperlipidemia, allergic rhinitis, and allergies to latex and betadine. Her social history was remarkable for recent exposure to COVID-19 through her husband who was hospitalized 1-month prior for COVID-19 positive pneumonia. At the time of exposure, she rapidly developed flu-like symptoms of myalgia, fatigue, nonproductive cough, and subjective low-grade fever within a week. She was seen at an urgent care facility where her vitals revealed 98\% oxygen saturation on room air, blood pressure of 130/60 $\mathrm{mmHg}$, and pulse of 70 beats per minute. Due to the evolving local, state, and federal guidelines, she did not meet COVID-19 diagnostic testing criteria at that time and was given a course of Azithromycin. Her cough improved, however she developed tachypnea and dyspnea on exertion, with persistence of her malaise and fever. Due to her lack of improvement, a chest x-ray was ordered which revealed a left lower lobe pneumonia. The patient was managed on outpatient cefdinir and albuterol. Nasopharyngeal COVID-19 swab and PCR analysis were performed and returned positive, confirming diagnosis of COVID-19 infection. Four-weeks after the onset of her respiratory symptoms, the patient noticed bilateral blue/grey discoloration of her proximal and distal foot phalanges, worse on the first and second digits, but no pain, 
pruritis, or loss of sensation (Fig. 1 and Fig. 2). 10 weeks after her initial COVID-19 diagnosis, her toe discoloration has resolved without any topical or oral treatment. (Fig. 3)

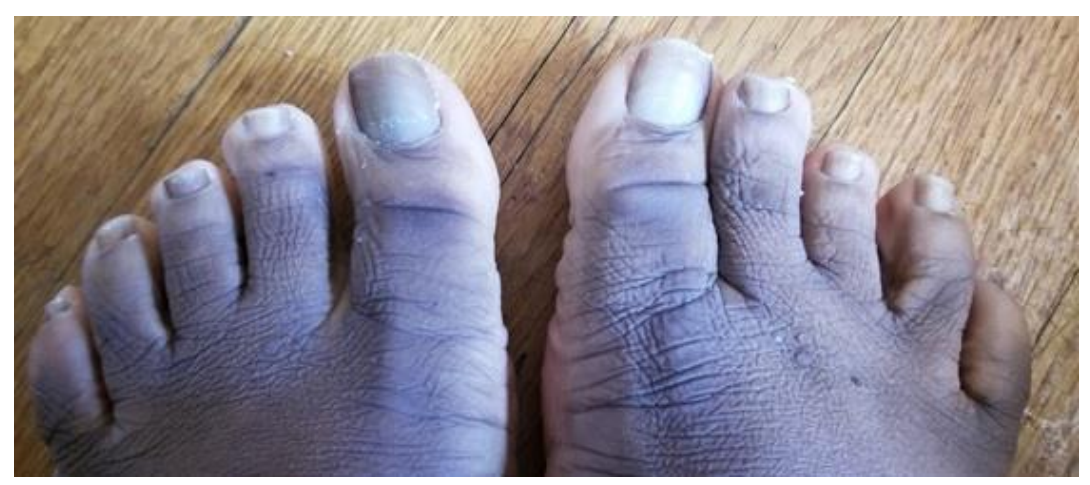

Figure 1: Picture of toes 7 weeks post-onset of COVID-19 symptoms.

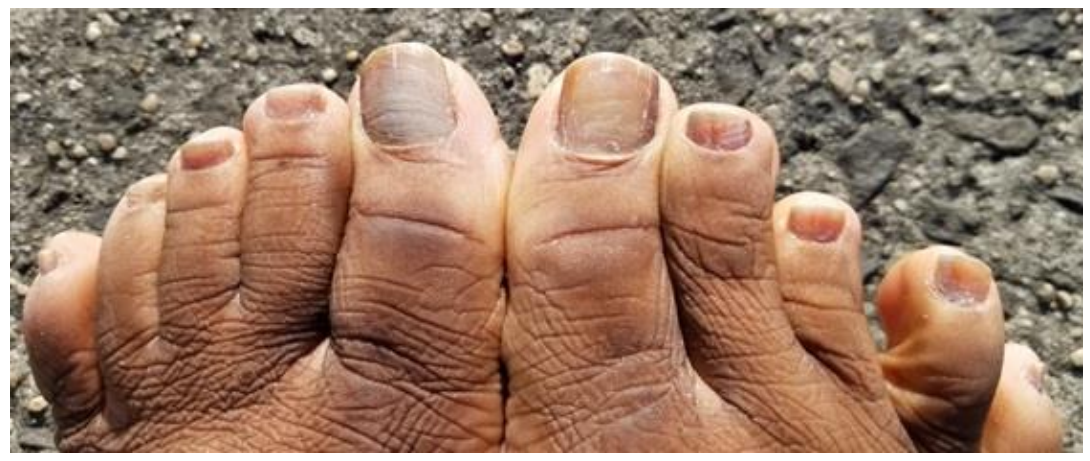

Figure 2: Picture of toes 9 weeks post-onset of COVID-19 symptoms.

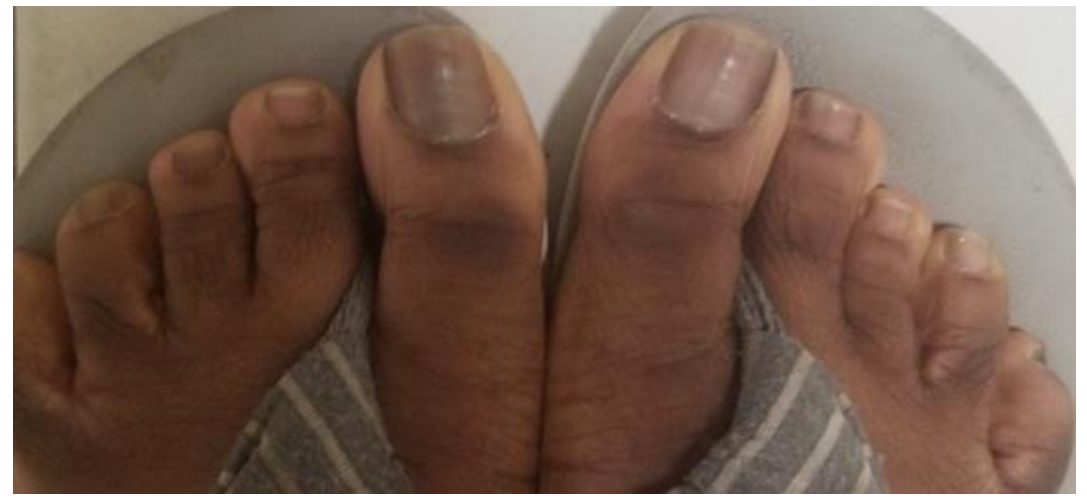

Figure 3: Picture of toes 10 weeks post-onset of COVID-19 symptoms, with subjective resolution of discoloration.

\section{Case 2}

A 9-year-old half Hispanic, half Asian male whose parents were both emergency medical technician first responders (both having tested COVID-19 antibody positive), presented to telemedicine dermatology clinic with a 3-week history of tender nodules of the toes. Past medical history was significant for attention deficit disorder, managed on methylphenidate, and asthma, well-managed on Beclomethasone 
and albuterol inhalers. Social history is significant for daily walks in cold weather during quarantine orders from March to April 2020. He was feeling well, afebrile, no malaise, asthenia or myalgias. For two weeks his right second toe, one week the 4 th toe on the right, and then the left foot second toe developed warm, tender erythematous nodules (Fig. 4). Initially severely tender and painful, the lesions caused difficulty with walking and weight bearing. He was treated with oral cephalexin $(40 \mathrm{mg} / \mathrm{kg} / \mathrm{day})$ for 10 days and the patient has had slow and steady improvement. The child was well managed with topical mometasone, local warming, and acetaminophen for pain. The patient was fully resolved without sequelae 4 weeks later.

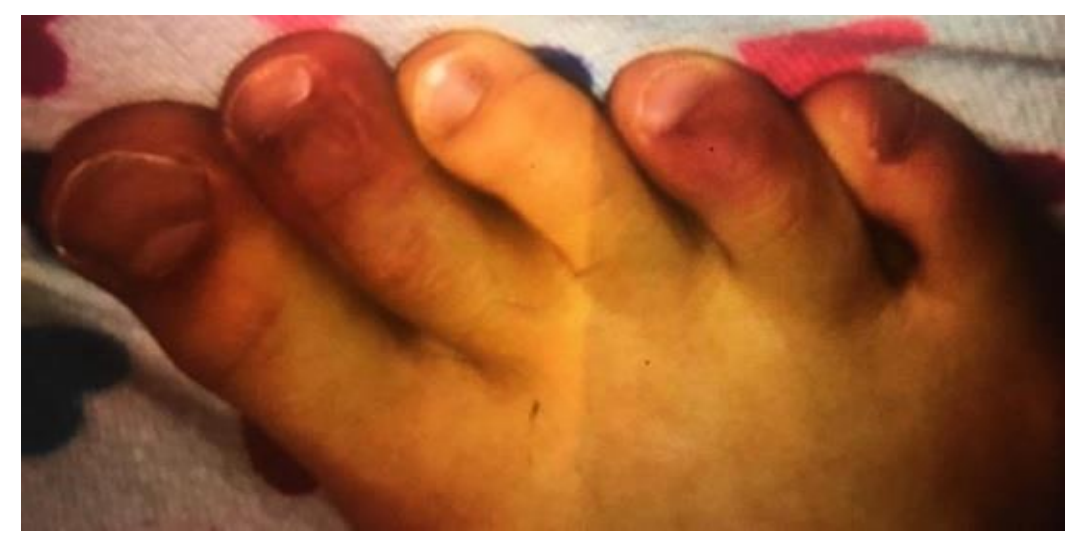

Figure 4: Picture of toes at start of symptoms, taken by patient's parent via telemedicine.

\section{Discussion}

COVID-19 is a global pandemic that has resulted in over 1.5 million infections and nearly 90 thousand deaths in the United States alone (Aggarwal et al., 2020). Age over 60, male gender, and racial minorities such as African Americans and Latino/Hispanic have been disproportionately affected by COVID-19, with higher rates of infection, hospitalization, and mortality (Department of H, Mental Hygiene C-RT, 2020; Yuan et al., 2020; CDC Covid Response Team, 2020). During its early stages, skin manifestations of COVID-19 were not widely recognized due to the focus on the more life-threatening disease processes of acute respiratory distress and pneumonia. Rapidly developing knowledge regarding asymptomatic carriers, comorbidities, and treatment have fueled varied COVID-19 approaches to containment and preventative measures (Adhikari et al., 2020). From the pandemic onset, new COVID-19 associated symptoms have been documented across various organ systems such as anosmia, ageusia, delirium, and diarrhea (Jin et al., 2020; Vaira et al., 2020). Dermatologically, COVID-19 mimics other viral exanthems, with reports demonstrating a spectrum that include, but are not limited to pseudo-chilblains, vesicular (varicella-like) eruptions, maculopapular rashes, urticarial lesions, and skin necrosis (Huang et al., 2020; Galván Casas et al., 2020; Cordoro et al., 2020). Due to the low sensitivity and scarcity of diagnostic testing during the early COVID-19 pandemic, various studies have accepted clinical diagnoses 
of COVID-19, further complicating attempts to correlate laboratory results with COVID skin manifestations (Zainol Rashid et al., 2020). In a recent study, 41\% of patients with COVID toes had a confirmed COVID-19 infection and serology, however patients with convincing physical exam and history of exposure have also tested negative for SARS-CoV2 RNA, which further obscures the role of testing in supporting diagnosis and quarantine recommendations (Galván Casas et al., 2020).

Despite these barriers, COVID toes or pseudo-chilblains, have recently come into focus in which patients have detailed painful, pernio-like acral lesions that are raised and discolored in patients of all ages (Nirenberg and Del Mar Ruiz Herrera, 2020; Cordoro et al., 2020). Typically emerging within a week of other COVID-19 symptoms, the etiology and subsequent pathophysiology of COVID toes are unknown and unlike classical chilblains, in which lesions occur due to small vessel inflammation in response to cold temperature or vitamin D deficiency (Piccolo et al., 2020; Shahi et al., 2015). The frequency of COVID toes is underestimated as many of the children with these features do not have other features of COVID-19 (Andina et al., 2020; Molloy and Bearer, 2020). Unclear reporting guidelines and underdiagnosis have estimates between 2\% to upwards of 20\% in all COVID-19 patients for COVID toes (Galván Casas et al., 2020; Cordoro et al., 2020; CDC Covid Response Team, 2020). Preliminary studies highlighted severe presentations in which peripheral ischemia resulted in acral cyanosis, gangrene, ulceration, or necrosis (Zhang et al., 2020). Patients were found to be in a hypercoagulable state with ultimately poor prognosis for recovery despite anticoagulation attempts (Zhang et al., 2020). In contrast, recent studies in Spain, the Middle East, and the United States have described a more benign course in which patients were generally younger and often asymptomatic (Galván Casas et al., 2020; Piccolo et al., 2020; Alramthan and Aldaraji, 2020). Minimal images of COVID toes have been shared of African American patients in the aforementioned studies, such that healthcare providers may have difficulty in identification of subtler presentations in darker skin tones (Buster et al., 2020). As seen with the first case patient, COVID toes may have an atypical appearance as her lesions were not painful, overtly swollen or enlarged, and had only mild discoloration relative to the surrounding skin. In contrast the nodules in the lighter skinned Hispanic/ Asian child are easily identified.

Continued research and reporting are needed to better understand COVID toes and associations in the COVID-19 disease process. It appears at this time that COVID toes may be a good prognostic indicator for recovery. However, as our adult patient demonstrates, patients can develop significant symptoms. Furthermore, clinical lesions may be more difficult to detect in patients of color. Implications regarding long term immunity are unknown. Early demographics for COVID-19 related hospitalizations and deaths have shown a higher prevalence among older or immunocompromised patients, particularly those with pre-existing health conditions(16). COVID toes of adults and children, appear to be of similar morphology 
and presentation as well as a good prognosis for recovery. Recent efforts by the American Academy of Dermatology's COVID-19 Dermatology Registry and large-scale studies are critical in deciphering how the virus affects skin differently among patients (Freeman et al., 2020). Current treatment for COVID toes mirror that of classical chilblains in which the off-label utilization and combination of high potency corticosteroids, analgesics and topical calcium channel blockers have had mixed results (Galván Casas et al., 2020). Usage of aspirin has been described in adults, however, risk of Reye's syndrome in children with aspirin usage limits prescribing (Prakash and Weisman, 2009).

\section{Conclusion}

COVID toes are a unique dermatological finding in COVID-19 patients, with a pseudo-chilblain appearance and course. As seen with the case patients, COVID toes can have a more classical morphology with painful, red lesions versus atypical ones with only discoloration and no pain. This spectrum of presentations coupled with the imprecision of COVID-19 testing complicates the ability for physicians to correlate COVID toes with a COVID-19 infection. Ongoing studies are continuously updating the body of knowledge in regard to COVID-19 and its extrapulmonary manifestations.

\section{References}

Adhikari SP, Meng S, Wu YJ, Mao YP, Ye RX, Wang QZ, Sun C, Sylvia S, Rozelle S, Raat H, Zhou H. Epidemiology, causes, clinical manifestation and diagnosis, prevention and control of coronavirus disease (COVID-19) during the early outbreak period: a scoping review. Infect Dis Poverty 2020; 9: 29.

Aggarwal S, Garcia-Telles N, Aggarwal G, Lavie C, Lippi G, Henry BM. Clinical features, laboratory characteristics, and outcomes of patients hospitalized with coronavirus disease 2019 (COVID-19): Early report from the United States. Diagnosis (Berl) 2020; 7: 91-6.

Ahn DG, Shin HJ, Kim MH, Lee S, Kim HS, Myoung J, Kim BT, Kim SJ. Current Status of Epidemiology, Diagnosis, Therapeutics, and Vaccines for Novel Coronavirus Disease 2019 (COVID-19). J Microbiol Biotechnol 2020; 30: 313-324.

Alramthan A and Aldaraji W. A case of COVID-19 presenting in clinical picture resembling chilblains disease. First report from the Middle East. Clin Exp Dermatol 2020.

Andina D, Noguera-Morel L, Bascuas-Arribas M, Gaitero-Tristán J, Alonso-Cadenas JA, Escalada-Pellitero S, Hernández-Martín Á, de la Torre-Espi M, Colmenero I, Torrelo A. Chilblains in children in the setting of COVID-19 pandemic. Pediatr Dermatol 2020.

Belhadjer Z, Méot M, Bajolle F, Khraiche D, Legendre A, Abakka S, Auriau J, Grimaud M, Oualha M, Beghetti M, Wacker J. Acute heart failure in multisystem inflammatory syndrome in children (MIS-C) in the context of global SARS-CoV-2 pandemic. Circulation 2020.

Buster KJ, Stevens EI, Elmets CA. Dermatologic health disparities. Dermatol Clin 2012; 30: 53-59.

CDC Covid Response Team. Severe Outcomes Among Patients with Coronavirus Disease 2019 (COVID-19) - United States, February 12-March 16, 2020. MMWR Morb Mortal Wkly Rep 2020; 69: 343-346. 
Cordoro KM, Reynolds SD, Wattier R, McCalmont TH. Clustered Cases of Acral Perniosis: Clinical Features, Histopathology and Relationship to COVID-19. Pediatr Dermatol 2020.

Freeman E. 'COVID-toes,' tracking dermatological symptoms of COVID-19. Healio Dermatology [Internet]. 2020. Available from: $\quad$ https://www.healio.com/dermatology/dermatitis/news/online/\%7B1f54025b-e860-4862-979d46daebae6818\%7D/covid-toes-tracking-dermatological-symptoms-of-covid-19.

Galván Casas C, Català A, Carretero Hernández G, Rodríguez-Jiménez P, Fernández Nieto D, Rodríguez-Villa Lario A, Navarro Fernández I, Ruiz-Villaverde R, Falkenhain D, Llamas Velasco M, García-Gavín J. Classification of the cutaneous manifestations of COVID-19: a rapid prospective nationwide consensus study in Spain with 375 cases. Br J Dermatol 2020.

Hamming I, Timens W, Bulthuis ML, Lely AT, Navis G, van Goor H. Tissue distribution of ACE2 protein, the functional receptor for SARS coronavirus. A first step in understanding SARS pathogenesis. J Pathol 2004; 203: 631-637.

Huang C, Wang Y, Li X, Ren L, Zhao J, Hu Y, Zhang L, Fan G, Xu J, Gu X, Cheng Z. Clinical features of patients infected with 2019 novel coronavirus in Wuhan, China. Lancet 2020; 395: 497-506.

Jin X, Lian JS, Hu JH, Gao J, Zheng L, Zhang YM, Hao SR, Jia HY, Cai H, Zhang XL, Yu GD. Epidemiological, clinical and virological characteristics of 74 cases of coronavirus-infected disease 2019 (COVID-19) with gastrointestinal symptoms. Gut 2020; 69: 1002-1009.

Lai CC, Liu YH, Wang CY, Wang YH, Hsueh SC, Yen MY, Ko WC, Hsueh PR. Asymptomatic carrier state, acute respiratory disease, and pneumonia due to severe acute respiratory syndrome coronavirus 2 (SARS-CoV-2): Facts and myths. J Microbiol Immunol Infect 2020.

Matrajt L and Leung T. Evaluating the Effectiveness of Social Distancing Interventions to Delay or Flatten the Epidemic Curve of Coronavirus Disease. Emerg Infect Dis 2020; 26.

Molloy EJ and Bearer CF. COVID-19 in children and altered inflammatory responses. Pediatr Res 2020.

New York City Department of H, Mental Hygiene C-RT. Preliminary Estimate of Excess Mortality During the COVID-19 Outbreak - New York City, March 11-May 2, 2020. MMWR Morb Mortal Wkly Rep 2020; 69: 603-605.

Nirenberg MS and Del Mar Ruiz Herrera M. Foot Manifestations in a COVID-19 Positive Patient: A Case Study. J Am Podiatr Med Assoc 2020.

Piccolo V, Neri I, Filippeschi C, Oranges T, Argenziano G, Battarra VC, Berti S, Manunza F, Belloni Fortina A, Di Lernia V, Boccaletti V. Chilblain-like lesions during COVID-19 epidemic: a preliminary study on 63 patients. J Eur Acad Dermatol Venereol 2020.

Prakash S and Weisman MH. Idiopathic chilblains. Am J Med 2009; 122: 1152-1155.

Prem K, Liu Y, Russell TW, Kucharski AJ, Eggo RM, Davies N, Flasche S, Clifford S, Pearson CA, Munday JD, Abbott S. The effect of control strategies to reduce social mixing on outcomes of the COVID-19 epidemic in Wuhan, China: a modelling study. Lancet Public Health 2020; 5: e261-e270.

Shahi V, Wetter DA, Cappel JA, Davis MD, Spittell PC. Vasospasm Is a Consistent Finding in Pernio (Chilblains) and a Possible Clue to Pathogenesis. Dermatology 2015; 231: 274-279.

Vaira LA, Salzano G, Deiana G, De Riu G. Anosmia and Ageusia: Common Findings in COVID-19 Patients. Laryngoscope 2020 .

Yuan X, Xu J, Hussain S, Wang H, Gao N, Zhang L. Trends and Prediction in Daily New Cases and Deaths of COVID-19 in the United States: An Internet Search-Interest Based Model. Explor Res Hypothesis Med 2020; 5: 1-6. 
Zainol Rashid Z, Othman SN, Abdul Samat MN, Ali UK, Wong KK. Diagnostic performance of COVID-19 serology assays. Malays J Pathol 2020; 42: 13-21.

Zhang Y, Cao W, Xiao M, Li YJ, Yang Y, Zhao J, Zhou X, Jiang W, Zhao YQ, Zhang SY, Li TS. Clinical and coagulation characteristics of 7 patients with critical COVID-2019 pneumonia and acro-ischemia. Zhonghua Xue Ye Xue Za Zhi 2020 ; 41 : E006. 